\title{
UPDATE Delayed ejaculation and alexithymia: what is the
}

\section{relationship? [version 2; peer review: 2 approved]}

\section{Paolo Maria Michetti ${ }^{1}$, Stefano Eleuteri ${ }^{2}$, Marta Giuliani ${ }^{3}$, Roberta Rossi ${ }^{3}$, Chiara Simonelli2}

\author{
1Department of Urology, Sapienza University of Rome, Roma, 155 - 00161, Italy \\ ${ }^{2}$ Faculty of Medicine and Psychology, Sapienza University of Rome, Roma, 1035 - 00189, Italy \\ ${ }^{3}$ Institute of Clinical Sexology, Roma, 78 - 00198, Italy
}

V2 First published: 07 Mar 2013, 2:81

https://doi.org/10.12688/f1000research.2-81.v1

Latest published: 20 May 2013, 2:81

https://doi.org/10.12688/f1000research.2-81.v2

\section{Abstract}

Delayed Ejaculation (DE) is probably the least studied and understood of the male sexual dysfunctions (MSD). There is still little unanimity concerning its psychological/interpersonal aetiology. Previous studies found that MSD are strongly related with alexithymia, a multifaceted personality construct that describes a disturbance in the regulation of emotions.The aim of this study was to investigate the presence of alexithymia in men with $D E$ and correlate alexithymia levels with $D E$ severity. According to specific features of the symptoms, we hypothesized that alexithymia would not be correlated with this specific sexual disorder.

54 outpatients with a diagnosis of DE assessed at the Institute of Clinical Sexology and the Urology Department of Sapienza, University in Rome were enrolled in the study. DE was diagnosed after a specialist examination and according to Diagnostic and Statistical Manual of Mental Disorders -IV-TR criteria. Participants were provided with the Toronto Alexithymia Scale (20 items; TAS-20), a self-measure of the Intravaginal Ejaculation Latency Time and an ad hoc questionnaire to collect anamnestic data.

9.3\% of patients could be categorized as alexithymics, $9.3 \%$ of them as borderline, while $81.4 \%$ of the sample was found to be non-

alexithymic. The overall average TAS-20 score was 45.46 . Results show that alexithymia is correlated neither with the presence of DE nor with its severity, in contrast to other MSDs, where this condition was found in about $30 \%$ of patients.

The data presented suggest that $\mathrm{DE}$, although not correlated to alexithymia, is probably related to other psychogenic features such as hypercontrol configuration. This paper can contribute to the understanding of $D E$, by excluding one of the possible etiological factors, previously found to be important in the onset and the maintenance of the other MSDs. More studies are needed in order to better understand DE and provide recommendations about treatment.

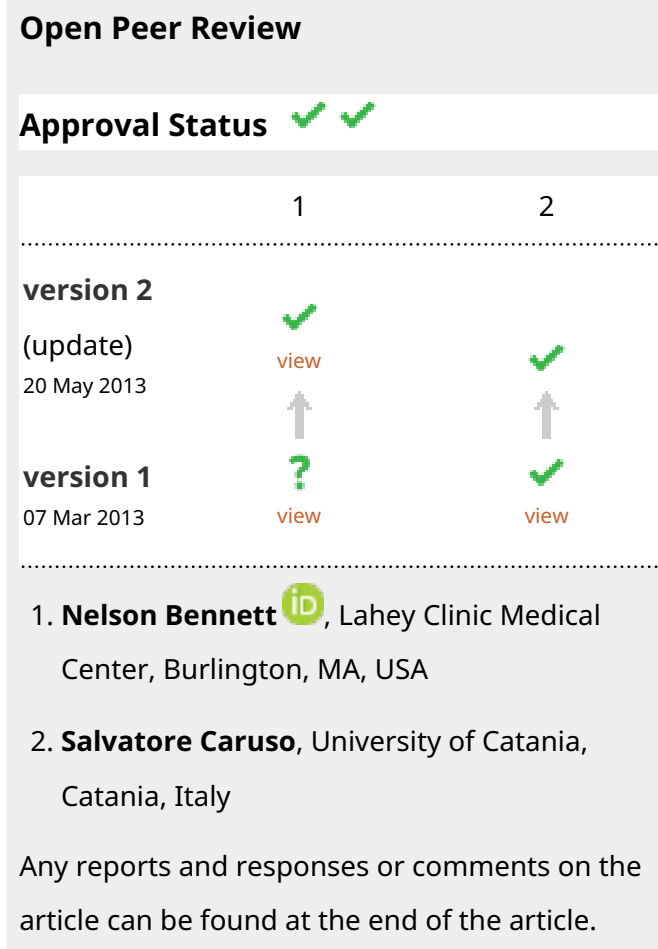

article can be found at the end of the article. 
Keywords

Delayed ejaculation, alexithymia, TAS

Corresponding authors: Stefano Eleuteri (stefano.eleuteri@gmail.com), Marta Giuliani (giuliani.marta@gmail.com)
Competing interests: No competing interests were disclosed.

Grant information: The present study was funded by the Department of Clinical and Dynamic Psychology, Faculty of Medicine and Psychology, Sapienza University of Rome.

The funders had no role in study design, data collection and analysis, decision to publish, or preparation of the manuscript.

Copyright: $\odot 2013$ Michetti PM et al. This is an open access article distributed under the terms of the Creative Commons Attribution License, which permits unrestricted use, distribution, and reproduction in any medium, provided the original work is properly cited. Data associated with the article are available under the terms of the Creative Commons Zero "No rights reserved" data waiver (CCO 1.0 Public domain dedication).

How to cite this article: Michetti PM, Eleuteri S, Giuliani M et al. Delayed ejaculation and alexithymia: what is the relationship? [version 2; peer review: 2 approved] F1000Research 2013, 2:81 https://doi.org/10.12688/f1000research.2-81.v2

First published: 07 Mar 2013, 2:81 https://doi.org/10.12688/f1000research.2-81.v1 


\section{UPDATED Changes from Version 1}

Upon the recommendation of referees Nelson Bennett and Salvatore Caruso, we have provided additional data that show the relationship between the three subfactors of TAS 20 and delayed ejaculation, including the results of the Spearmans Rho correlations we have done. We also have updated the data-set with the scores for the subfactors and the total scores of TAS 20.

\section{See referee reports}

\section{Introduction}

Delayed Ejaculation (DE) is probably the least studied and understood of the Male Sexual Dysfunctions (MSD) ${ }^{1}$. However, its negative impact is significant as it typically results in lack of sexual fulfilment for both the man and his partner; the problem is further increased when procreation is among the couple's goals of sexual intercourse. The terms delayed, retarded, inadequate or inhibited ejaculation, idiopathic anejaculation (inability to ejaculate) and psychogenic anejaculation have all been used synonymously to describe a delay or absence of male orgasm ${ }^{2}$. The Diagnostic and Statistical Manual of Mental Disorders-IV-TR ${ }^{3}$ defines DE as:

"the persistent or recurrent delay in, or absence of, orgasm after a normal sexual excitement phase during sexual activity that the clinician, taking into account the person's age, judges to be adequate in focus, intensity, and duration. The disturbance causes marked distress or interpersonal difficulty".

In the literature $\mathrm{DE}$ is reported to have an incidence rate between $3 \%$ and almost $40 \%$, depending on age and comorbidities ${ }^{4-8}$. The essential medical causes of this problem include neurogenic, infective, endocrine and medication factors ${ }^{9}$. Psychological and interpersonal aspects are also involved in the onset and maintenance of DE, but there is little unanimity concerning these causes ${ }^{1}$.

Previous studies have found that Hypoactive Sexual Desire Disorder (HSDD), Erectile Dysfunction (ED) and Premature Ejaculation $(\mathrm{PE})$ are strongly correlated with alexithymia ${ }^{10-14}$. Alexithymia (from the ancient Greek "a" for lack, "lexis" for word, and "thymos" for emotion) is a multifaceted personality construct introduced in the early 1970 s by Nemiah and Sifneos ${ }^{15,16}$. The alexithymia construct describes a set of deficits in the cognitive processing of emotions, or more generally, a disturbance in the regulation of emotions ${ }^{17}$. The personality features that characterize alexithymic individuals include difficulty in identifying emotions and differentiating between emotions and the bodily sensations of emotional arousal; difficulty in communicating emotions to others; reduced imaginal and fantasy activity and an externally oriented cognitive style, a sub-factor of the alexithymia construct involving impoverished fantasy life, utilitarian thinking and a focus on external concrete data of the sensate environment $^{18,19}$.

A deep analysis of the literature underlines that:

- $20-25 \%$ of subjects presenting MSDs can be classified as alexithymics $^{10-13}$;

- there is a significant correlation between alexithymia and the length/severity of MSD symptoms ${ }^{12-14}$;
- alexithymia is particularly correlated with $\mathrm{HSDD}^{10}, \mathrm{ED}^{10,12}$ and $\mathrm{PE}^{13}$.

The aim of this study was to investigate the presence of alexithymia in men with DE and to correlate alexithymia levels with DE severity. According to specific features of the symptoms we hypothesize that alexithymia will not be associated with this specific sexual disorder. In fact, emotional control, an important clinical feature identified in DE conceptualization ${ }^{20,21}$, has been found to be negatively associated with alexithymia ${ }^{22,23}$.

\section{Methods}

60 outpatients with a diagnosis of DE assessed at the Institute of Clinical Sexology and at the Urology Department of Sapienza, University in Rome were enrolled in the study. DE was diagnosed after a specialist examination, i.e. a careful anamnesis and a physical examination, and according to DSM-IV-TR criteria.

Patients with previous and current psychotherapeutic experiences (6 patients) were not included because of the possible influence of psychotherapy on the degree of alexithymia ${ }^{19}$. Participants were informed in detail about the study, guaranteed confidentiality and anonymity and advised of their right to withdraw at any time. The ones who gave their consent to participate were provided with a research protocol including the following measures. The research protocol received institutional approval.

DE severity was evaluated using a self-reported Intravaginal Ejaculation Latency Time (IELT; ${ }^{24}$ ) measure. The participants were given the following options to categorise the latency time: 10-20 mins, 20-30 mins, 30-40 mins, 40-50 mins and 'never reached orgasm'.

A questionnaire collecting demographic, anamnestic data and characteristics of the symptom (Lifelong or Acquired, Situational or Generalized DE) was filled by all patients. Alexithymia was measured by the 20 -item Toronto Alexithymia Scale (TAS-20) ${ }^{25,26}$, a validated tool used to evaluate alexithymia levels. Even though alexithymia levels are measured on a continuous scale, different studies have established standard cut-off scores to distinguish alexithymic (TAS-20 $\geq 61$ ) from non-alexithymic subjects (TAS-20 $\leq 51$ ), with a borderline area for scores between 51 and $61^{19}$. The scale has a factor structure that reflects three separate, yet conceptually related, facets of the alexithymia construct ${ }^{25}$. The three factors are difficulty identifying feelings and distinguishing them from the somatic sensations that accompany emotional arousal (Subfactor 1), difficulty communicating feelings to other people (Subfactor 2) and externally oriented thinking (Subfactor 3).

Using SPSS version 19 (IBM-SPSS Inc., 2010, Chicago, IL, USA), descriptive analyses were run in order to check sample and symptom characteristics. The relationship between alexithymia level and DE severity was investigated by Spearman's Rho correlation coefficient.

\section{Results}

Table 1 shows the demographic characteristics of the respondents. The majority were in a relationship, employed, and had attended at least secondary school. Descriptive analysis (Table 2) revealed that the great majority of the patients presented a lifelong $(73.3 \%)$ and generalized (90.6\%) DE. Moreover, half of the patients declared 


\section{Table 1. Demographic characteristics of the respondents.}

\begin{tabular}{|ll|}
\hline Description & Value \\
\hline Age (Mean \pm SD) & $36.31 \pm 9.09$ \\
\hline Relationship status (\%) & \\
\hline Single & 20.4 \\
\hline In relationship & 79.6 \\
\hline Professional status (\%) & \\
\hline Employed & 79.2 \\
\hline Unemployed & 5.7 \\
\hline Student & 15.1 \\
\hline Education (\%) & \\
\hline Primary School & 9.3 \\
\hline Secondary School & 42.6 \\
\hline University & 48.1 \\
\hline
\end{tabular}

that they had never reached orgasm, reporting that ejaculation was impossible. $81.4 \%$ of the sample was found to be non-alexithymic, with an overall average TAS-20 score of 45.46 .

TAS scores did not significantly correlate with the severity of DE measured by IELT $(p=0.54)$. Total TAS scores and the scores of the three different subfactors did not significantly correlate with the severity of DE measured by IELT (respectively $\mathrm{p}=0.54 ; \mathrm{p}=0.95$; $\mathrm{p}=0.47 ; \mathrm{p}=0.24)$.

Updated version 2: Delayed ejaculation and alexithymia: raw data

1 Data File

http://dx.doi.org/10.6084/m9.figshare.703572

\section{Discussion}

Problems with "difficulty" in ejaculating may vary from a delay in the latency to ejaculation to a complete inability to ejaculate (anejaculation). According to the literature, we used the term Delayed Ejaculation (DE) to describe any and all ejaculatory disorders with either a long latency or absence of ejaculation ${ }^{3}$ : our sample was composed of $50 \%$ of patients with delayed ejaculation and $50 \%$ that could not ejaculate. Furthermore, we found that $73.3 \%$ of the sample presented lifelong DE: this data is in strong contrast with the literature, where around $25 \%$ of patients suffer from lifelong DE, with the remainder reporting it as acquired ${ }^{7,27,28}$.

According to our hypothesis, the results show that the alexithymia construct does not seem to be correlated with DE (only 9.3\% of the patients could be classified as alexithymics), in contrast to other MSDs, where this condition was found in about $30 \%$ of patients, specifically it was found in $23 \%$ for suffering from
Table 2. Descriptive statistics of patients diagnosed with delayed ejaculation.

\begin{tabular}{ll}
\hline $\begin{array}{l}\text { Patient characteristic } \\
\text { Delayed ejaculation }\end{array}$ & $\%$ \\
\hline Lifelong & 73.3 \\
\hline Acquired & 26.7 \\
\hline Generalized & 90.6 \\
\hline Situational & 9.4 \\
\hline IELT & \\
\hline 10-20 min & 9.3 \\
\hline 20-30 min & 7.4 \\
\hline 30-40 min & 22.2 \\
\hline 40-50 min & 11.1 \\
\hline Never reached orgasm & 50 \\
\hline Alexithymia & \\
\hline Non-Alexithymic & 81.4 \\
\hline Borderline & 9.3 \\
\hline Alexithymic & 9.3 \\
\hline TAS scores did not significantly correlate with the severity \\
of DE measured by IELT ( $=0.54)$ IELT -Intravaginal \\
\hline Ejaculation Latency Time.
\end{tabular}

HSDD, in $25 \%$ of them with PE and $34 \%$ of the ones declaring to have $\mathrm{ED}^{10-13}$.

There is some evidence supporting the inadequacy of alexithymia as an etiological factor in DE pathogenesis. From the first psychodynamic interpretations, DE has been associated with obsessive traits ${ }^{20,21}$, in which emotional control has an important role. This hyper-control configuration in men presenting DE has also been strongly confirmed in our psychotherapeutic experience for this disorder. In the clinical setting it is very common that patients with DE present a wide range of control behaviours, which affect not only their sexual experience, but also their daily activities and relations. This control is indiscriminately projected over emotions, behaviour and thoughts. The presence of this control presumes that the person recognizes his emotional responses, a trait that is typically absent in subjects with alexithymia. Indeed alexithymia and emotional control were previously found to be negatively associated $^{22,23}$. This finding could explain the low rates of alexithymic traits in our sample.

The lack of difficulty in identifying and communicating emotions to others in patients with DE may also be connected to the greater social acceptance of DE than Premature Ejaculation and Erectile Dysfunction: the symptom does not seem to affect core male identity. From a somatopsychic perspective, the consequent low individual and relational distress arising from DE conditions could represent an important protective factor from creating or exacerbating high levels of alexithymia. 
More research is still necessary to understand and treat DE. There is a strong need for more studies examining the precipitating and maintaining factors of this problem. Controlled and randomized outcome studies, using validated measures with sufficient followup periods, are necessary to determine the psychogenic variables connected with the onset and the maintenance of DE and the most efficacious methods of psychological treatment. The present studies are inadequate to make evidence-based recommendations about treatment ${ }^{1}$.

This paper can contribute to the understanding of DE by excluding one of the possible etiological factors that has been previously found to be important in the onset and the maintenance of other MSDs.

\section{Consent}

Written informed consent was obtained from all study participants before receiving the research protocol. Each subject was advised of own right to withdraw at any time.

\section{Author contributions}

$\mathrm{RR}, \mathrm{MG}$ and SE conceived the study. CS designed the experiments. PMM, MG and SE carried out the research. RR and CS contributed to the design of experiments. MG and SE prepared the first draft of the manuscript. PMM, RR and CS contributed to the experimental design and preparation of the manuscript, supervising the study. All authors were involved in the revision of the draft manuscript and have agreed to the final content.

\section{Competing interests}

No competing interests were disclosed.

\section{Grant information}

The present study was funded by the Department of Clinical and Dynamic Psychology, Faculty of Medicine and Psychology, Sapienza University of Rome (Code: C26A12K7SS).

The funders had no role in study design, data collection and analysis, decision to publish, or preparation of the manuscript.
1. Althof SE: Psychological interventions for delayed ejaculation/orgasm. Int J Impot Res. 2012; 24(4): 131-6. PubMed Abstract | Publisher Full Text

2. Rowland D, McMahon CG, Abdo C, et al:: Disorders of orgasm and ejaculation in men. J Sex Med. 2010; 7(4 Pt 2): 1668-86. PubMed Abstract | Publisher Full Text

3. American Psychiatric Association. Diagnostic and statistical manual of mental disorders, DSM-IV-TR. 4th edition, revised. American Psychiatric Association. Washington DC: 2000

Reference Source

4. Cruz N, Porst $\mathrm{H}$ : Ejaculatory and orgasmic disorders other then premature ejaculation. in Porst $\mathrm{H}$, Reisman Y. (Eds), The ESSM Syllabus of Sexual Medicine European Society for Sexual Medicine (ESSM) and Medix Publishers BV: 2012; 736-789.

5. Lindau ST, Schumm LP, Laumann EO, et al:: A study of sexuality and health among older adults in the United States. N Engl J Med. 2007; 357(8): 762-774. PubMed Abstract | Publisher Full Text | Free Full Text

6. Jannini EA, Lenzi A: Ejaculatory disorders: epidemiology and current approaches to definition, classification and subtyping. World J Urol. 2005; 23(2): 68-75. PubMed Abstract | Publisher Full Text

7. Perelman MA: Retarded Ejaculation. Curr Sex Health Rep. 2004; 1(3): 95-101. Publisher Full Text

8. Simons JS, Carey MP: Prevalence of sexual dysfunctions: results from decade of research. Arch Sex Behav. 2001; 30(2): 177-219. PubMed Abstract | Publisher Full Text | Free Full Text

9. McMahon CG, Rowland D, Abdo C, et al.: Disorders of orgasm and ejaculation in men. in Montorsi F, Basson R, Adaikan G et al. (Eds). Sexual Medicine: Sexual Disorders in Men and Women Edition 2010: Paris, J Sex Med. 2010; 7(4 Pt 2): 1668-86. PubMed Abstract | Publisher Full Text

10. Madioni F, Mammana LA: Toronto Alexithymia Scale in outpatients with sexual disorders. Psychopathology. 2001; 34(2): 95-8.

PubMed Abstract | Publisher Full Text

11. Wise TN, Osborne $\mathrm{C}$, Strand $\mathrm{J}$, et al:: Alexithymia in patients attending a sexual disorders clinic. J Sex Marital Ther. 2002; 28(5): 445-50. PubMed Abstract | Publisher Full Text

12. Michetti PM, Rossi R, Bonanno D, et al:: Male sexuality and regulation of emotions: a study on the association between alexithymia and erectile dysfunction (ED). Int J Impot Res. 2006; 18(2): 170-4. PubMed Abstract | Publisher Full Text

13. Simonelli C, Bonanno D, Michetti PM, et al:: Premature ejaculation and dysregulation of emotions: research and clinical implication. Sexologies. 2008; 17(1): 18-23. Publisher Full Text

14. Reid RC, Carpenter BN, Spackman M, et al.: Alexithymia, emotional instability, and vulnerability to stress proneness in patients seeking help for hypersexual behavior. J Sex Marital Ther. 2008; 34(2): 133-149. PubMed Abstract | Publisher Full Text
15. Nemiah JC, Sifneos PE: Affect and fantasy in patients with psychosomatic disorders. in Hill O (Ed). Modern trends in psychosomatic medicine (vol. 2). London: Butterworths; 1970; 26-43.

16. Nemiah JC, Freyberger H, Sifneos PE: Alexithymia: a view of the psychosomatic process. in Hill O (Ed). Modern trends in psychosomatic medicine (vol. 3). London: Butterworths; 1976; 430-9.

17. Taylor GJ, Bagby RM, Parker JD: The alexithymia construct: a potential paradigm for psychosomatic medicine. Psychosomatics. 1991; 32(2): 153-164. PubMed Abstract | Publisher Full Text

18. Taylor GJ, Bagby RM, Ryan DP, et al:: Validation of the alexithymia construct: a measurement-based approach. Can J Psychiatry. 1990; 35(4): 290-7. PubMed Abstract

19. Taylor GJ, Bagby RM, Parker JD: Disorders of Affect Regulation: Alexithymia in Medical and Psychiatric Illness. Cambridge: Cambridge University Press; 1997; 7(3): 240. Publisher Full Text

20. Abraham G, Marrama P, Carani C, et al:: Psychoneuroendocrinologie du plasir Simep s.a., Lyon-Villeurbanne: Paris; 1985.

21. Rowland DL, Keeney C, Slob AK: Sexual response in men with inhibited or retarded ejaculation. Int J Impot Res. 2004; 16(3): 270-4. PubMed Abstract | Publisher Full Text

22. Verissimo R, Mota-Cardoso R, Taylor G: Relationships between alexithymia, emotional control, and quality of life in patients with inflammatory bowel disease. Psychother Psychosom. 1998; 67(2): 75-80. PubMed Abstract | Publisher Full Text

23. Verissimo R: [Emotional intelligence: from alexithymia to emotional control]. Acta Med Port. 2003; 16(6): 407-11. PubMed Abstract

24. Waldinger MD, Zwinderman AH, Olivier B, et al.: Proposal for a definition of lifelong premature ejaculation based on epidemiological stopwatch data. J Sex Med. 2005; 2(4): 498-507. PubMed Abstract | Publisher Full Text

25. Bagby RM, Parker JD, Taylor GJ: The twenty-item Toronto Alexithymia Scale--I. Item selection and cross validation of the factor structure. J Psychosom Res. 1994; 38(1): 23-32. PubMed Abstract | Publisher Full Text

26. Bressi C, Taylor G, Parker J, et al:: Cross validation of the factor structure of the 20-item Toronto Alexithymia Scale: an Italian multicentre study. J Psychosom Res. 1996; 41(6): 551-9. PubMed Abstract | Publisher Full Text

27. Perelman MA, Rowland DL: Retarded ejaculation. World J Urol. 2006; 24(6): 645-52. PubMed Abstract | Publisher Full Text

28. Abdel-Hamid IA, Saleh el-S: Primary lifelong delayed ejaculation: characteristics and response to bupropion. J Sex Med. 2011; 8(6): 1772-9. PubMed Abstract | Publisher Full Text 


\section{Open Peer Review}

\section{Current Peer Review Status:}

\section{Version 2}

Reviewer Report 06 March 2014

https://doi.org/10.5256/f1000research.1509.r3991

(c) 2014 Caruso S. This is an open access peer review report distributed under the terms of the Creative Commons Attribution License, which permits unrestricted use, distribution, and reproduction in any medium, provided the original work is properly cited.

\section{Salvatore Caruso}

Department of Medical Surgical Specialties, University of Catania, Catania, Italy

Competing Interests: No competing interests were disclosed.

I confirm that I have read this submission and believe that I have an appropriate level of expertise to confirm that it is of an acceptable scientific standard.

Reviewer Report 21 May 2013

https://doi.org/10.5256/f1000research.1509.r960

(c) 2013 Bennett N. This is an open access peer review report distributed under the terms of the Creative Commons Attribution License, which permits unrestricted use, distribution, and reproduction in any medium, provided the original work is properly cited.

\section{Nelson Bennett}

Institute of Urology, Lahey Clinic Medical Center, Burlington, MA, USA

The manuscript is much improved.

Competing Interests: No competing interests were disclosed.

I confirm that I have read this submission and believe that I have an appropriate level of expertise to confirm that it is of an acceptable scientific standard.

\section{Version 1}


Reviewer Report 17 April 2013

https://doi.org/10.5256/f1000research.1229.r898

(C) 2013 Caruso S. This is an open access peer review report distributed under the terms of the Creative Commons Attribution License, which permits unrestricted use, distribution, and reproduction in any medium, provided the original work is properly cited.

\section{Salvatore Caruso}

Department of Medical Surgical Specialties, University of Catania, Catania, Italy

The research is very interesting because it focuses the attention on the relationship between emotional regulation and delayed ejaculation. The emerged results supply an appreciable suggestion for the clinical practice underlining how different male sexual disorders could be influenced by different emotional patterns.

The self-report questionnaire the Authors used, beyond the total alexithymia score, provides three separate, yet conceptually related, facets of the alexithymia construct: difficulty identifying feelings and distinguishing them from the somatic sensations that accompany emotional arousal (F1), difficulty communicating feelings to other people (F2) and externally oriented thinking (F3).

Despite the data revealed negative correlation between alexithymia and delayed ejaculation, the study would be stronger if the Authors could specify if the same negative trend emerges also correlating delayed ejaculation levels with the three sub-factors

Competing Interests: No competing interests were disclosed.

\section{I confirm that I have read this submission and believe that I have an appropriate level of expertise to confirm that it is of an acceptable scientific standard.}

Author Response ( ) 05 May 2013

Stefano Eleuteri, Sapienza University of Rome, Roma, Italy

Dr. Caruso, these are the results of the Spearman's Rho correlation for the 3 subfactors of TAS 20 , to be included in the 'Results' section: $F 1$ ( $\rho s=-0.010, p=0.95), F 2$ ( $\rho s=-0.101$, $p=0.47), F 3$ ( $\rho s=-0.164, p=0.24)$.

Competing Interests: No competing interests were disclosed.

Reviewer Report 14 March 2013

https://doi.org/10.5256/f1000research.1229.r837 
(c) 2013 Bennett N. This is an open access peer review report distributed under the terms of the Creative Commons Attribution License, which permits unrestricted use, distribution, and reproduction in any medium, provided the original work is properly cited.

\section{Nelson Bennett}

Institute of Urology, Lahey Clinic Medical Center, Burlington, MA, USA

The authors seek to define the relationship of alexithymia to delayed orgasm. This is an excellent research question that needs to be answered in order to advance our knowledge psychosexual disorders. The study design and methods are appropriate.

The study would be stronger if the results of the Spearman's Rho correlation were included in the 'Results' section. This would lend more support to the study conclusions. In reality, without the coefficient data, the data does support not the conclusion of the manuscript.

Competing Interests: No competing interests were disclosed.

\section{I confirm that I have read this submission and believe that I have an appropriate level of expertise to confirm that it is of an acceptable scientific standard, however I have significant reservations, as outlined above.}

Author Response ( ) 20 Mar 2013

Stefano Eleuteri, Sapienza University of Rome, Roma, Italy

Dr. Bennett, these are the results of the Spearman's Rho correlation, to be included in the 'Results' section: $\rho s=-0.086, p=0.54$.

Competing Interests: No competing interests were disclosed. 
The benefits of publishing with F1000Research:

- Your article is published within days, with no editorial bias

- You can publish traditional articles, null/negative results, case reports, data notes and more

- The peer review process is transparent and collaborative

- Your article is indexed in PubMed after passing peer review

- Dedicated customer support at every stage

For pre-submission enquiries, contact research@f1000.com 